\title{
Effect of Inoculum Density and Soil Tillage on the Development and Severity of Rhizoctonia Root Rot
}

\author{
K. L. Schroeder and T. C. Paulitz
}

USDA-ARS Root Disease and Biological Control Unit, Washington State University, Pullman 99164-6430. Accepted for publication 26 October 2007.

\begin{abstract}
Schroeder, K. L., and Paulitz, T. C. 2008. Effect of inoculum density and soil tillage on the development and severity of Rhizoctonia root rot. Phytopathology 98:304-314.

Rhizoctonia spp. cause substantial yield losses in direct-seeded cereal crops compared with conventional tillage. To investigate the mechanisms behind this increased disease, soils from tilled or direct-seeded fields were inoculated with Rhizoctonia spp. at population densities from 0.8 to 250 propagules per gram and planted with barley (Hordeum vulgare). The incidence and severity of disease did not differ between soils with different tillage histories. Both $R$. solani AG-8 and $R$. oryzae stunted plants at

high inoculum densities, with the latter causing pre-emergence dampingoff. High inoculum densities of both species stimulated early production of crown roots in barley seedlings. Intact soil cores from these same tilled and direct-seeded fields were used to evaluate the growth of Rhizoctonia spp. from colonized oat seeds. Growth of $R$. oryzae was not affected by previous tillage history. However, $R$. solani AG-8 grew more rapidly through soil from a long-term direct-seeded field compared to tilled soils. The differential response between these two experiments (mixed, homogenized soil versus intact soil) suggests that soil structure plays a major role in the proliferation of $R$. solani AG-8 through soils with different tillage histories.
\end{abstract}

Rhizoctonia root rot of wheat and barley is caused by Rhizoctonia solani Kühn and $R$. oryzae Ryker \& Gooch. $R$. solani AG-8 is responsible for bare patch symptoms, whereas both species can cause chronic root rot resulting in stunted plants and reduced vigor. Previous work indicated that $R$. oryzae was less important; causing minor symptoms compared to $R$. solani AG-8 and failing to substantially reduce plant development $(20,36)$. However, more recent work indicates that $R$. oryzae is prevalent in wheat and barley. In a 2001 survey conducted in eastern Washington, $R$. oryzae represented over half of the Rhizoctonia isolates recovered (26). Under certain conditions, $R$. oryzae can cause substantial plant damage, and is also capable of causing damping-off of wheat and barley seedlings $(3,18,27,28)$.

Rhizoctonia root rot was first described in the Pacific Northwest (PNW) in the mid-1980s (39). The pathogens causing this disease are ubiquitous in the PNW (4) and control measures are limited. There is no known natural resistance (37) and minimal control is obtained with chemical seed treatments (5). Control of this disease is currently restricted to cultural management strategies, including elimination of volunteer plants and weeds at least 2 to 3 weeks prior to planting $(30,31,35)$, use of phosphorus starter fertilizers with the seed at planting (4), and tillage (16). However, a recent trend in the PNW is to convert from conventional tillage to direct seeding, thereby making the latter of these control strategies less desirable from a soil management perspective. Direct seeding involves planting into the previous year's stubble without tillage so the only soil disturbance is from the planter passing through the field. Direct seeding offers a number of benefits, including reduced soil erosion, improved water infiltration, and reduced input costs (labor and fuel) (2). Despite the improvements in soil quality and the reduced production costs,

Corresponding author: T. C. Paulitz; E-mail address: paulitz@wsu.edu

doi:10.1094/PHYTO-98-3-0304

This article is in the public domain and not copyrightable. It may be freely reprinted with customary crediting of the source. The American Phytopathological Society, 2008 many growers in the PNW are still reluctant to convert to direct seeding due to the fear of increased root disease. Many previous studies have demonstrated an increase in Rhizoctonia root rot with direct seeding $(16,29,32,39)$; however, little is known about the reasons for the increased disease. Our previous work documented that this increase in $R$. solani occurs in the third year of the transition from conventional to direct-seeding, resulting in significantly decreased yields in the third and fourth year (33). It is speculated that disease incidence is lower in tilled soils because soil cultivation disrupts the mycelial network of Rhizoctonia spp., resulting in reduced pathogen vigor (26). Drying of soil following tillage is also hypothesized to be responsible for reduced activity of Rhizoctonia spp. and subsequent reductions in disease (26). Less disease in tilled fields may also be a result of microbial suppression of Rhizoctonia spp. following a flush of nutrients associated with incorporating plant debris into the soil, stimulating microbial growth.

The underlining mechanisms that result in increased disease caused by Rhizoctonia spp. within direct-seeded fields are unknown. Changes in soil structure may influence spread of the pathogen in soil. In a study of various soil types, greater rates of $R$. solani AG-8 growth were observed through sandy soils than sandy clay loams (11). Similarly, Otten et al. (21) found reduced growth in soils with a higher bulk density and reduced aggregate size. The soil microbial community may also be influenced by tillage and have an indirect effect on the spread of the pathogen. The goal of this research was to determine whether soils managed by long-term conventional tillage or direct seeding differed in their ability to support Rhizoctonia root rot or the growth of Rhizoctonia spp. through soils. This was accomplished by measuring disease caused by varying inoculum densities of $R$. solani and $R$. oryzae added to soils collected from fields with different tillage histories. The growth and spread of Rhizoctonia spp. from point sources of inoculum added to intact soil cores taken from conventionally tilled and direct-seeded fields were also measured. In essence, both techniques attempted to compare pathogen behavior in conventionally tilled versus direct-seeded soils. In the first case, the natural field soil was sieved so the natural soil structure 
was destroyed, but in the second experiment with intact soil cores, the soil structure was maintained.

\section{MATERIALS AND METHODS}

Soil collection. Soils were collected from the ARS Palouse Conservation Farm (19 years of direct seeding, $5 \mathrm{~km}$ northwest of Pullman, WA) and the Cook Agronomy Farm (formerly Cunningham Agronomy Farm, 3 years of direct seeding, $8 \mathrm{~km}$ northeast of Pullman WA). At each location, soils were randomly removed from each of three sites spaced about $15 \mathrm{~m}$ apart in both a conventionally tilled field and a direct-seeded field. At each sampling site, the top $15 \mathrm{~cm}$ of soil was collected using a shovel and transported in 19-liter buckets. Each sampling site served as a replicate in subsequent studies. Soils from all locations were a Thatuna fine silty loam. Soils were sieved to a particle size of $2 \mathrm{~mm}$ or less prior to infestation with inoculum of Rhizoctonia spp.

Inoculum preparation. Rhizoctonia inoculum was prepared as described by Paulitz and Schroeder (25). Briefly, $250 \mathrm{ml}$ of whole oats was mixed with $250 \mathrm{ml}$ of distilled water in 1-liter flasks and autoclaved for $90 \mathrm{~min}$ on two consecutive days. The oats were inoculated with eight $1-\mathrm{cm}$ agar plugs from a 4- to 5-day-old potato dextrose agar culture of either $R$. solani AG-8 isolate C-1 (18), or $R$. oryzae isolate 0801387 (26). The inoculated oats were incubated at room temperature for 5 weeks and were shaken weekly to evenly distribute colonized oat kernels. The inoculum was air dried for 3 days, ground, and sieved to obtain particle sizes between 250 and $1,000 \mu \mathrm{m}$.

Inoculum density/disease assay. The sieved soils collected from field sites were infested with $R$. solani or $R$. oryzae using six concentrations in the first experiment and seven concentrations in the second experiment. These concentrations included $0,0.8,2.5$, $8.0,25$, and 80 propagules per gram (ppg) in the first experiment, with the addition of $250 \mathrm{ppg}$ in the second experiment. The infested soils were placed into $3.8-\mathrm{cm}$ diameter $\times 21 \mathrm{~cm}$ depth (164 ml volume) conetainers (Stuewe and Sons, Inc., Corvallis, OR) (120 g of soil/conetainer) and watered with $30 \mathrm{ml}$ of water. One barley seed (cv. Baronesse) was placed on the soil surface in each tube and covered with $1 \mathrm{~cm}(\approx 16 \mathrm{~g})$ of noninoculated soil. Conetainers were arranged in a randomized complete block design, with three blocks and five containers per block. The conetainers were covered with clear polyethylene plastic until emergence (6 to 7 days) and plants were grown for a total of 18 days at $15^{\circ} \mathrm{C}$ with a 12 -h photoperiod. Plants were watered 2 days after emergence and then at 2- to 3-day intervals to maintain a conetainer weight within $5 \%$ of the initial weight.

At harvest, plants were removed from the soils and washed gently. Plant height and number of seminal and crown roots were recorded, and the roots were examined for disease incidence and severity using a 0 to 8 disease rating scale with the following criteria (13): $0=$ no lesions, $1=<50 \%$ of the roots with a single lesion, $2=<50 \%$ of the roots each with a few lesions, $3=>50 \%$ of the roots each with one or more lesions, $4=<50 \%$ of the roots with lesions within $1 \mathrm{~cm}$ of the seed, $5=>50 \%$ of the roots with lesions within $1 \mathrm{~cm}$ of the seed, $6=>50 \%$ of the roots with terminal lesions less than $3 \mathrm{~cm}$ from the seed, $7=>50 \%$ of the roots with terminal lesions less than $1 \mathrm{~cm}$ from the seed, and $8=$ $100 \%$ of the roots with terminal lesions less than $1 \mathrm{~cm}$ from the seed. In addition, digital images of the roots were produced by scanning with an Epson Expression 1680 equipped with a transparency adapter and analyzing the root images using WinRHIZO (Régents Instruments, Inc., Québec, Canada). This experiment was conducted twice using soils collected in 2002 and 2003.

Growth of Rhizoctonia spp. in intact soil cores. To evaluate the growth of Rhizoctonia spp. through soil, intact soil cores were obtained from the locations described above at the ARS Palouse Conservation Farm and the Cook Agronomy Farm. The soil cores were $15-\mathrm{cm}$ diameter $\times 20$ to $22 \mathrm{~cm}$ deep inside a $15.5 \times 26-\mathrm{cm}$
PVC plastic pipe. The cores were collected using a Giddings probe mounted to a John Deere 550 crawler. A mesh screen $(1.5 \mathrm{~mm})$ was attached to the bottom of the soil cores to keep the cores intact. At each location, soils cores were removed from each of five sites spaced about $15 \mathrm{~m}$ apart in both a conventionally tilled field and a direct-seeded field. Cores were collected in the fall of both 2002 and 2003 to use in replicate studies. Soils were also collected from each of the above locations for bulk density measurements. At each location, four cores were removed from each of five sites spaced about $15 \mathrm{~m}$ apart. Cores consisted of $2.5-\mathrm{cm}$ diameter by $12.5 \mathrm{~cm}$ long.

The soil cores were infested with either $R$. solani AG-8 isolate C-1 or $R$. oryzae isolate 0801387 by placing three colonized whole oats into the center of each core at a depth of about $3 \mathrm{~cm}$, causing minimal disturbance to the soil. Two barley seeds (cv. Baronesse) were placed $1 \mathrm{~cm}$ above the inoculum and eight additional seeds were sown to a depth of $2 \mathrm{~cm}$ in a radial pattern at $4 \mathrm{~cm}$ from the center seeds (about half way between the center and edge of the cores) (Fig. 1). The cores were arranged in a randomized complete block design, with five blocks. The cores were placed in a temperature-controlled growth room at $15^{\circ} \mathrm{C}$ with a 12-h photoperiod. Growth of the Rhizoctonia spp. was measured at weekly intervals, starting immediately after placing the inoculum in the pots and planting the barley seed (time zero). The growth and relative populations of Rhizoctonia spp. were determined by baiting the fungi out of the soil using toothpicks $(14,25)$ placed at $1-\mathrm{cm}$ intervals from the source of inoculum outwards. Each week, one of eight transects was randomly selected and round toothpicks were placed into the soil to a depth of $5.5 \mathrm{~cm}$ for $48 \mathrm{~h}$, the toothpicks were removed and placed onto Rhizoctonia selective medium (RSM: per liter; $20 \mathrm{~g}$ of agar, $100 \mathrm{mg}$ of chloramphenicol, and $1 \mathrm{mg}$ of Benlate 80DF), and the plates were incubated in the dark for $24 \mathrm{~h}$. Plates were examined

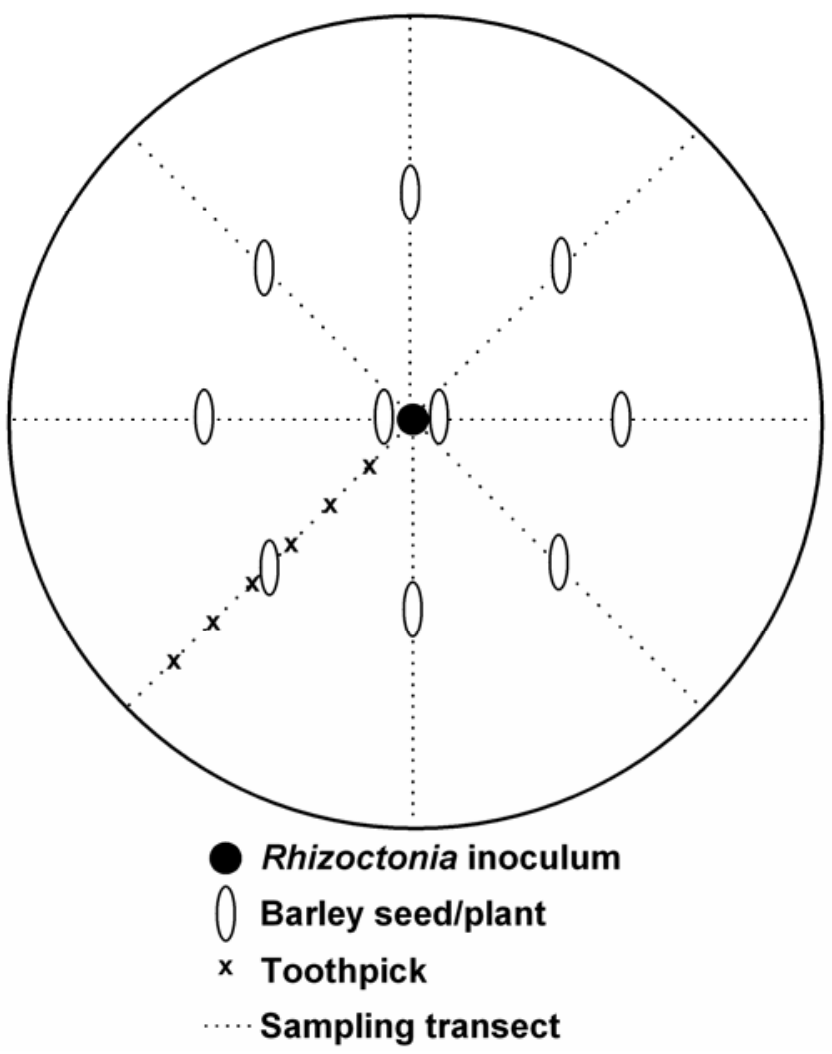

Fig. 1. Diagrammatic representation of experimental design for growth of Rhizoctonia spp. through intact soil cores. Samples were removed at weekly intervals, sampling along a different transect (represented by dotted lines) each week. 
using a dissecting microscope (Olympus SZ 10-40X) and colonies of Rhizoctonia spp. growing out of the toothpicks were enumerated. The number of colonies growing out from the toothpicks was estimated using a 5-mm grid beneath the plate. If the grid square contained mycelium of $R$. solani or $R$. oryzae, it was counted as one colony. $R$. solani AG- 8 colonies were identified by typical $90^{\circ}$ branching of the hyphae, with a constriction in hyphal diameter and a septation near the branching point. $R$. oryzae was identified by lateral branches growing from of the main hyphae at an angle of 30 to $50^{\circ}$ and rapid growth on selective media $(\approx 1 \mathrm{~cm}$ within $24 \mathrm{~h}$ ). In addition, the hyphae of both species were relatively thick. Fungal colonies not readily identifiable were confirmed by removing a portion of the hyphae and examining under a light microscope.

Data analysis. For inoculum density studies, means and standard errors were calculated from three replications of five plants. Data were graphed, transforming the inoculum density (ppg of soil) to a logarithmic scale after the addition of 1 to each value. For each variable, a regression analysis was performed using a three-parameter logistic or sigmoidal model. Regressions were generated using SigmaPlot version (Systat Software, Inc., San Jose, CA). Comparisons of regression variables from plants grown in tilled and direct-seeded soils as well as comparisons between $R$. solani and $R$. oryzae were made using multivariate analysis of variance (PROC MANOVA) and Wilks' Lambda test at a $P=$ 0.05 . The difference in the number of roots between inoculum densities was evaluated individually for each soil/tillage combina- tion using general linear models (PROC GLM) and when appropriate mean comparisons were made using Fisher's least significant difference (LSD) at $P=0.05$. Bulk density data was also analyzed using PROC GLM and means compared using LSD. Correlation analyses were conducted on variables recorded from $R$. solani AG-8- and $R$. oryzae-infected barley plants using the Pearson product-moment correlation analysis. For the growth of Rhizoctonia spp. through intact soil cores, means were calculated from five replicate cores for each pathogen-soil combination. All analyses were performed using SAS version 9.1 (SAS Institute Inc., Cary, NC).

\section{RESULTS}

The inoculum density/disease assay used to compare the soils from tilled and direct-seeded locations was conducted twice. The data from the second replication of the experiment are presented in this paper. The trends were similar in the first replication of the experiment, with the only difference between soils from tilled and direct-seeded fields being observed in Cook Agronomy Farm soils inoculated with $R$. oryzae. In these soils, there was a smaller loss of roots, lower disease rating and less root length loss in the tilled soils. However, this difference was not significant in any of the comparisons $(P=0.05)$ and the differences appear to be largely due to poor disease development in one replication of the experiment.

Inoculum density/disease assay. Use of inoculum densities from 0 to $250 \mathrm{ppg}$ resulted in a range of disease incidence and

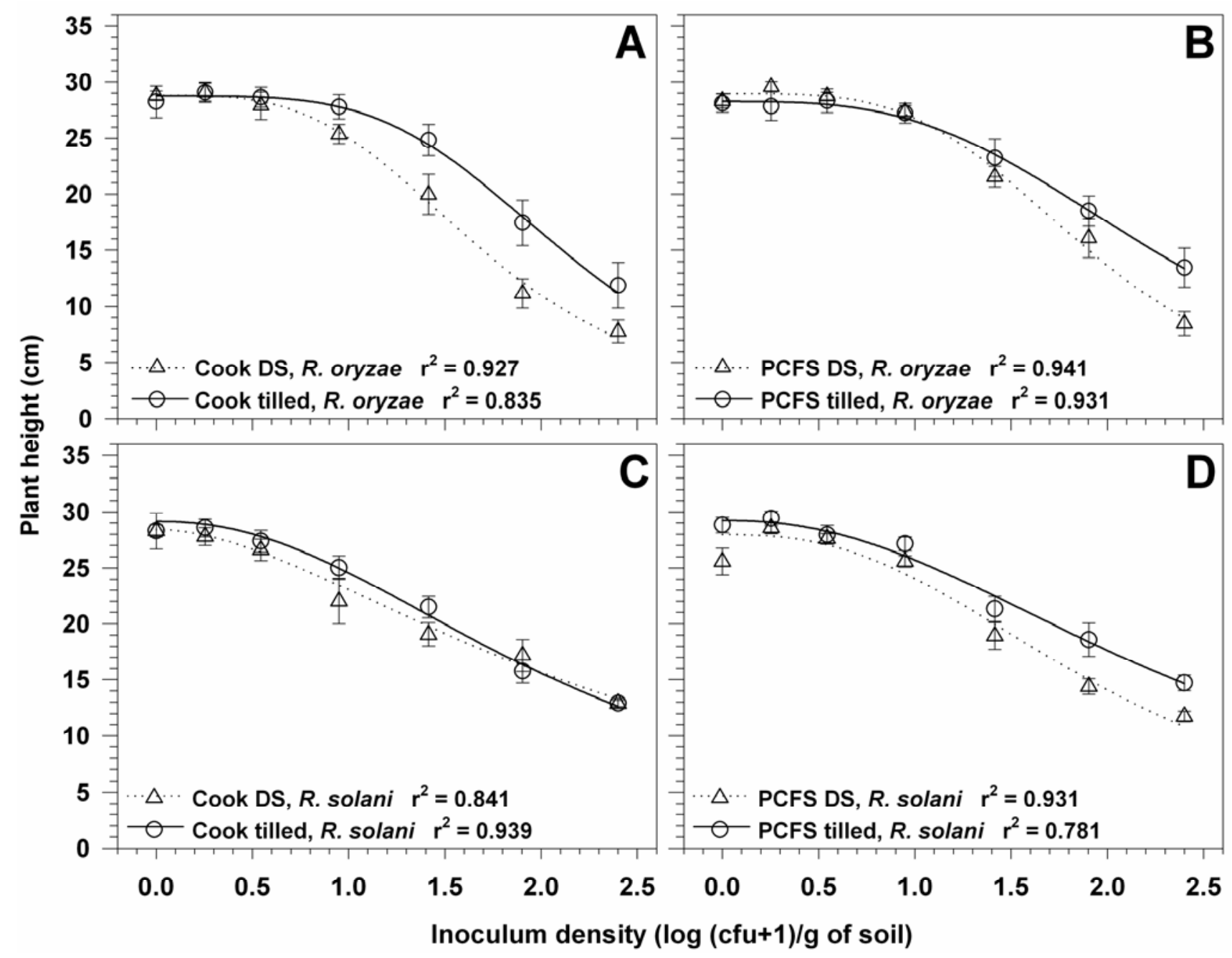

Fig. 2. Plant height of barley grown in soils from the Cook Agronomy Farm (A, C) and ARS Palouse Conservation Farm (PCFS) (B, D). Soils were inoculuted with Rhizoctonia oryzae (A, B) or R. solani (C, D). Error bars were calculated from the standard error of the mean. 
severity on barley plants, from very low to severe. The total number of roots, percentage of roots infected with Rhizoctonia root rot, root rot disease ratings, and total root length differed little between soils removed from conventionally tilled or direct-seeded fields. However, differences were evident between barley plants grown in soils inoculated with $R$. solani versus $R$. oryzae.

Plant height decreased with increasing inoculum density for both $R$. solani and $R$. oryzae inoculum. When compared with the noninfested control, barley plants grown in soil with $250 \mathrm{ppg}$ of $R$. solani were reduced in height by 49 to $54 \%$ (Fig. 2 C and D). Plants grown in $R$. oryzae-infested soils exhibited a higher degree of stunting at the higher inoculum densities and when compared with the noninfested control, plants were reduced in height by 52 to $73 \%$ (Fig. 2A and B). In addition, greater stunting was associated with barley plants grown in soils from direct-seeded fields that were infested with greater than $25 \mathrm{ppg}$ of $R$. oryzae compared to soils from conventionally tilled fields, although this difference was not significant.

The total number of roots (seminal and crown) was counted. There was no difference in the number of roots between conventionally tilled and direct-seeded soils with either $R$. oryzae or $R$. solani at the Cook Agronomy Farm or ARS Palouse Conservation Farm (Fig. 3). The only exception to this was a significant increase $(P=0.007)$ in crown root production by barley plants grown in tilled soils compared with direct-seeded soils from the Cook Agronomy Farm, which was evident particularly at inoculum densities of 80 and $250 \mathrm{ppg}$. An average of six seminal roots was generally recorded for healthy plants grown in noninfested soil, with few or no crown roots produced. Likewise, plants grown in soils infested with $R$. solani had approximately six seminal roots regardless of the inoculum density (Fig. 3C and D). However, with increasing inoculum, the number of crown roots increased from 0 in the noninfested control soils to an average of 1.6 crown roots per plant in soils infested with $80 \mathrm{ppg}$, with inoculum densities higher than 8 ppg resulting in significantly more crown roots in all soil/tillage combinations. A similar trend was found when plants were grown in soils infested with $R$. oryzae (Fig. 3A and B). However, with increasing inoculum density of $R$. oryzae, the number of seminal roots declined from approximately six per plant in the control and lower inoculum densities ( 0.8 to $8 \mathrm{ppg}$ ) to 1.7 to 3.2 seminal roots per plant at $250 \mathrm{ppg}$, with significantly fewer seminal roots at 80 and $250 \mathrm{ppg}$. The total number of crown roots increased with higher inoculum densities of $R$. oryzae, reaching a maximum of 1.6 roots per plant with $250 \mathrm{ppg}$. As observed with $R$. solani, the number of crown roots per plant in $R$. oryzae-infested soils was significantly increased by 8 ppg or more in all soil/tillage combinations with the exception of tilled soil from the Cook Agronomy Farm, which was 25 ppg or more.

Root damage was assessed directly by assigning a disease rating ( 0 to 8 scale) to each root system. Disease ratings differed little between soils from direct-seeded versus conventionally tilled fields (Fig. 4). In soils infested with $R$. solani, disease ratings ranged from 0.7 to 1.7 in the $0.8 \mathrm{ppg}$ treatment to a maximum

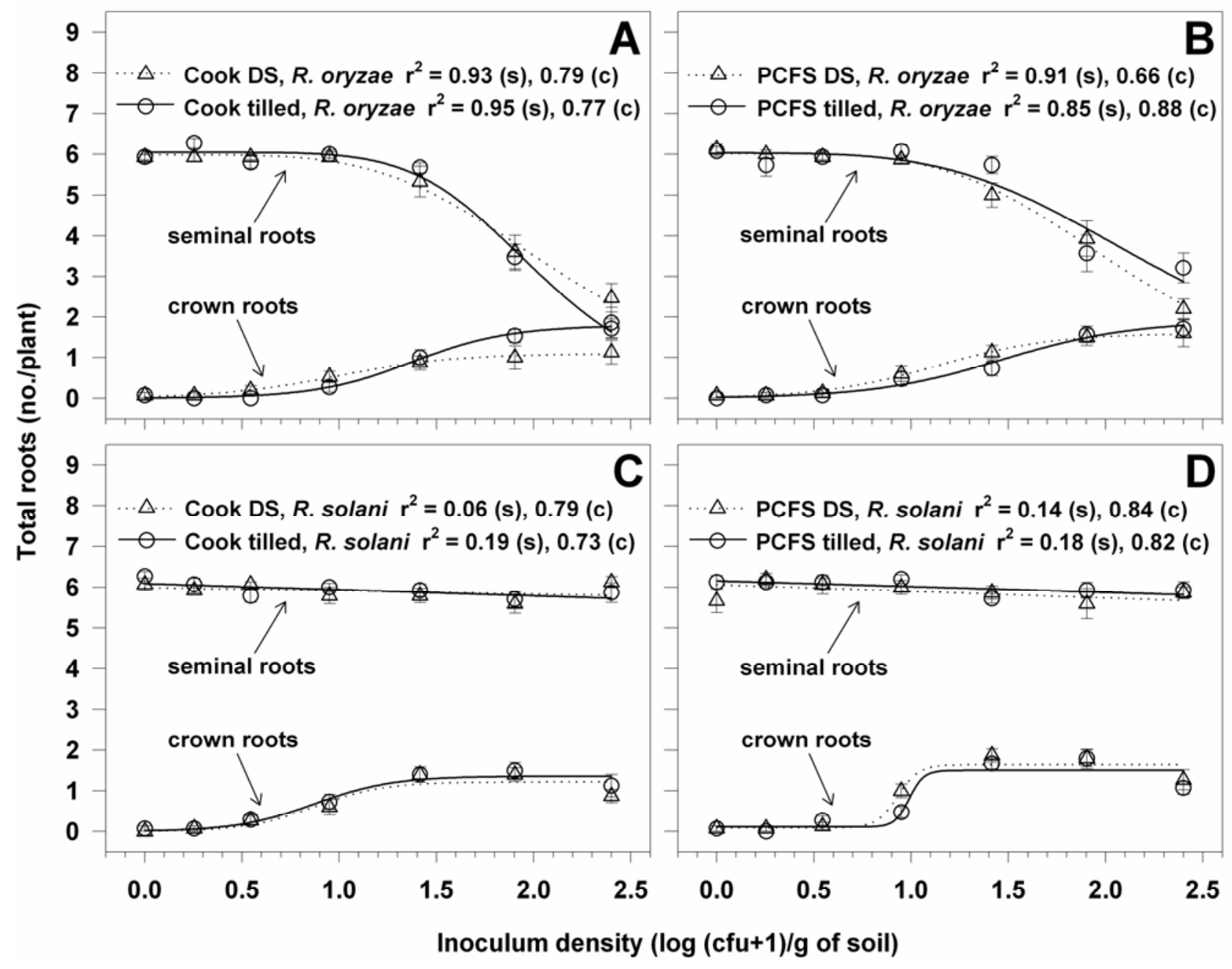

Fig. 3. Number of roots for barley grown in soils from the Cook Agronomy Farm (A, C) and ARS Palouse Conservation Farm (PCFS) (B, D). Soils were inoculuted with Rhizoctonia oryzae $(\mathbf{A}, \mathbf{B})$ or $R$. solani $(\mathbf{C}, \mathbf{D})$. For $r^{2}$ values, $\mathrm{s}=$ seminal root and $\mathrm{c}=$ crown root. Error bars were calculated from the standard error of the mean. 
disease rating of 5.4 to 7.1 in the $80 \mathrm{ppg}$ treatment. Infection with $R$. oryzae resulted in slightly higher disease ratings, reaching at least 7.1 with 80 to $250 \mathrm{ppg}$ of inoculum in both experiments. The previous tillage history of a field did not affect disease ratings for plants grown in Rhizoctonia-infested soils from either ARS Palouse Conservation Farm or the Cook Agronomy Farm, with the exception of significantly more disease $(P=0.012)$ on plants grown in direct-seeded soil from the ARS Palouse Conservation Farm.

The total root length was calculated using WinRHIZO as another assessment of disease damage and illustrated as the percentage of the total root length of Rhizoctonia-inoculated plants compared to plants grown in the noninfested soil (Fig. 5). The total root length did not differ with previous soil management history with the exception of substantially greater root loss on plants grown in $R$. oryzae-infested soils from the direct-seeded site at the Cook Agronomy Farm (Fig. 5A). Both pathogens caused significant root loss; however, at moderate inoculum densities (8 to $25 \mathrm{ppg}), R$. solani-infested soils resulted in significantly $(P<$ $0.0001)$ greater loss of total root length than $R$. oryzae.

The inoculum density study was analyzed using Pearson's correlation analysis for variables measured from barley plants grown in soils infested with $R$. solani AG-8 (Table 1) and $R$. oryzae (Table 2 ). With $R$. solani AG- 8 -infected plants, a high degree of correlation was observed for all variables with the exception of seminal root numbers, which had a low, but significant correlation with other variables. There were particularly high cor- relations between the percentage of infected seminal roots and the number of tips $(\mathrm{r}=-0.77)$, root length $(\mathrm{r}=-0.77)$, and the disease rating $(\mathrm{r}=0.91)$. The disease rating was also highly correlated with the number of tips $(r=-0.84)$ and total root length $(r=$ -0.78). All correlations of variables from $R$. oryzae-infected barley plants were highly significant (Table 2 ). As with $R$. solaniinfected plants, the percentage of infected seminal roots was highly correlated with the number of root tips $(\mathrm{r}=-0.67)$ and the disease rating $(r=0.89)$. The disease rating was also highly correlated with the number of root tips $(r=-0.80)$. However, the relationship between the total root length and the percentage of infected seminal roots $(\mathrm{r}=-0.55)$ and disease rating $(\mathrm{r}=-0.59)$ were not correlated as highly as the same comparisons with $R$. solani-infected plants. At the higher inoculum densities, many of the plants infected with $R$. oryzae had poor seminal root growth, but typically one or two robust crown roots, which might explain the lower correlation with total root length from $R$. oryzaeinfected barley plants. Unlike $R$. solani-infected plants, plants infected with $R$. oryzae exhibited decreasing numbers of seminal roots with increasing inoculum density, resulting in a higher correlation of variables with this measurement. The high correlation between disease ratings and number of tips and total root length indicates that analysis of roots by WinRHIZO provides a good estimate of root damage caused by Rhizoctonia spp.

Growth of Rhizoctonia spp. in intact soil cores. Growth of Rhizoctonia spp. through intact soil cores was monitored over the course of 6 weeks. For both $R$. oryzae and $R$. solani, the number

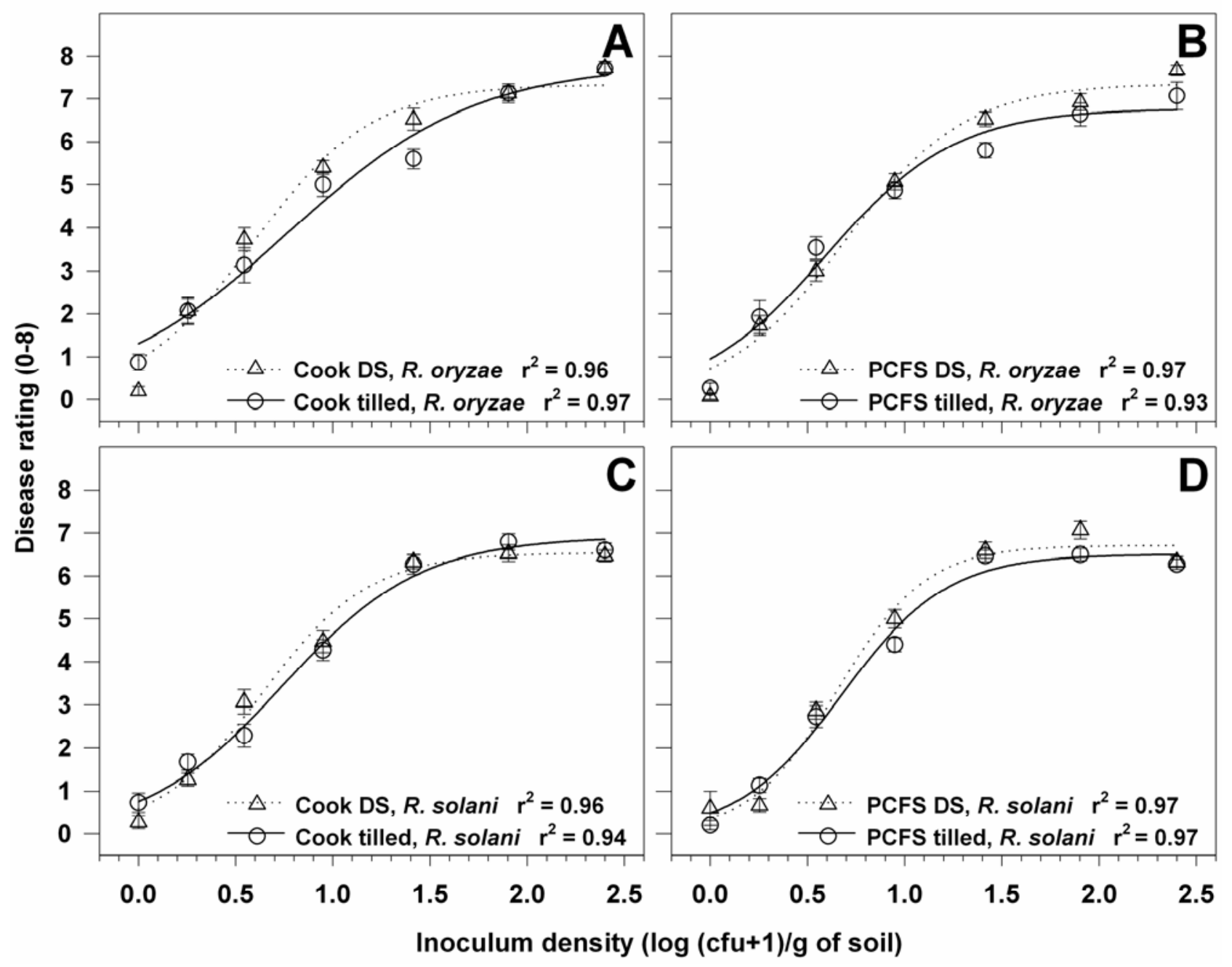

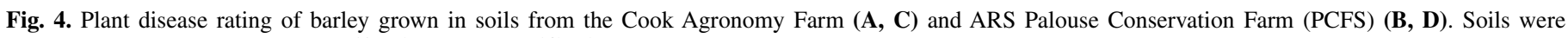
inoculuted with Rhizoctonia oryzae $(\mathbf{A}, \mathbf{B})$ or $R$. solani $(\mathbf{C}, \mathbf{D})$. Error bars were calculated from the standard error of the mean. 
of colonies per toothpick from each transect within the soil cores and time point was recorded. $R$. oryzae was found to have very minimal growth in all replications of the experiment. $R$. oryzae did not grow more than $2 \mathrm{~cm}$ through intact soil cores, and the number of colonies per toothpick declined within 2 weeks following infestation of the soils (Fig. 6). In some cases, $R$. oryzae was not recovered from the site of the infested oat seed 3 weeks after placing the inoculum. The growth of $R$. oryzae in conventionally tilled and direct-seeded soil did not differ substantially, although $R$. oryzae was generally recovered more frequently from conventionally tilled soils.

More substantial growth was observed with $R$. solani AG-8, with the fungus generally reaching $6 \mathrm{~cm}$ of growth within 5 weeks (Fig. 7). Similar rates of spread were observed through soil cores removed from conventionally tilled and direct-seeded portions of both research farms. However, more extensive colonization was seen in soil cores removed from conventionally tilled sites at the Cook Agronomy Farm (Fig. 7D) and direct-seeded sites at the ARS Palouse Conservation Farm (Fig. 7A). Bulk density measurements taken from these two farms revealed a significantly lower bulk density of the direct-seeded soil at the ARS Palouse Conservation Farm and a slightly higher bulk density of the direct-seeded soil at the Cook Agronomy Farm (Fig. 8). The bulk density of the tilled soils was similar between the two locations.

The growth of Rhizoctonia spp. through intact soil cores was repeated with a second set of cores from each of the same loca- tions. Very similar trends as those described above were observed, although there was reduced growth of $R$. solani in the replicate study, with growth generally not exceeding $3 \mathrm{~cm}$ from the site of inoculation. Growth of $R$. oryzae was very minimal, with reduction in recovery after 2 weeks and more growth in tilled soils from both the ARS Palouse Conservation Farm and the Cook Agronomy Farm. Despite reduced growth of $R$. solani in the replicate study, there was a greater recovery in the direct-seeded soils from the ARS Palouse Conservation Farm and the tilled soils at the Cook Agronomy Farm, as was observed in the first trial of this experiment.

Prior to initiating the above experiments, a single core was randomly selected from each of the four locations and subjected to the toothpick assay to look for background populations of Rhizoctonia spp. The native populations in these soils were found to be negligible and did not impact the quantification of growth from the artificial inoculum added to the cores.

\section{DISCUSSION}

Rhizoctonia root rot often increases during the transition from conventional tillage to direct seeding, but the exact reason for this is unknown. In this study, the impact of soil from tilled or directseeded fields on inoculum density/disease relationships of Rhizoctonia spp. was examined. Soils were sieved to obtain a uniform structure, with similar textures. Thus, differences observed be-

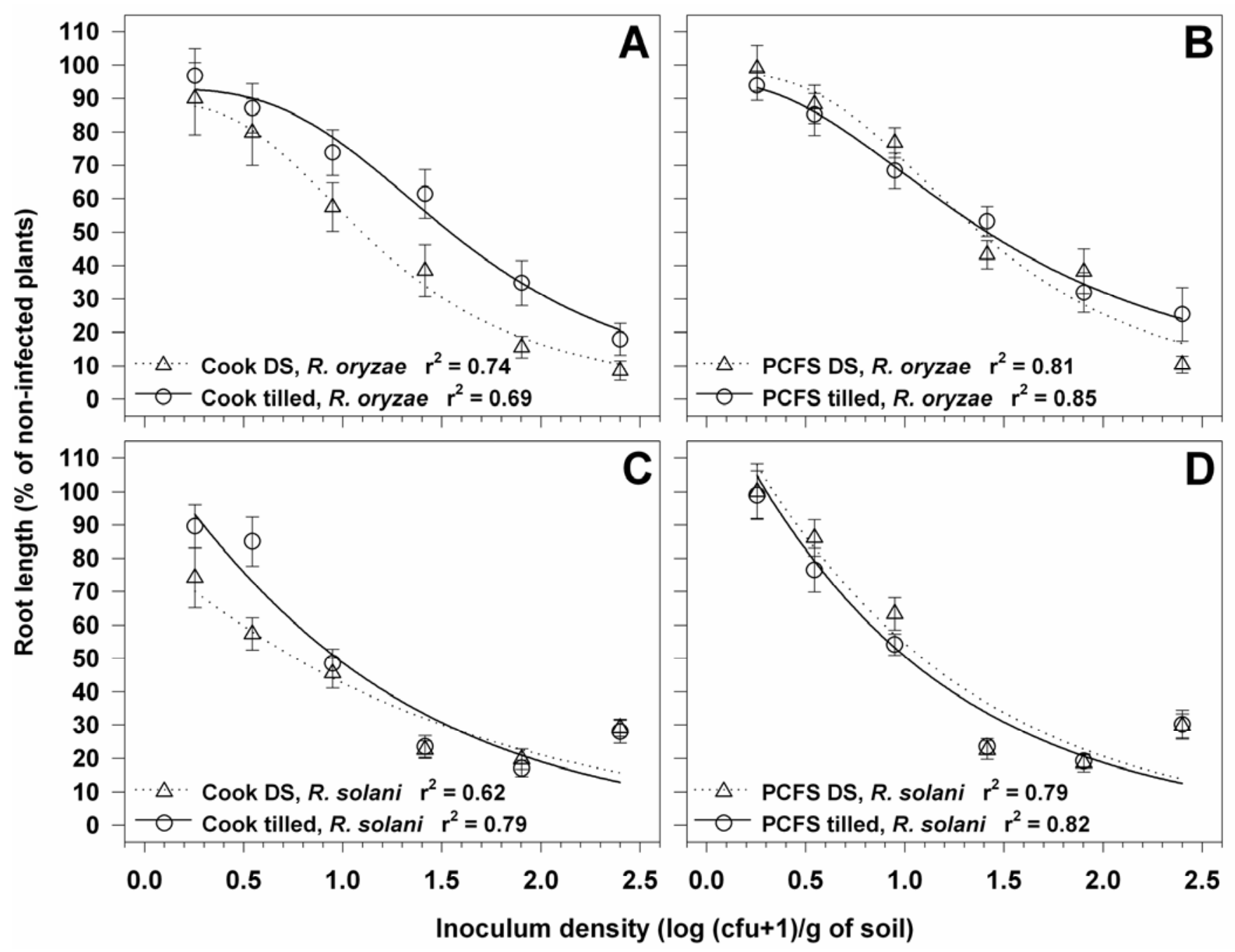

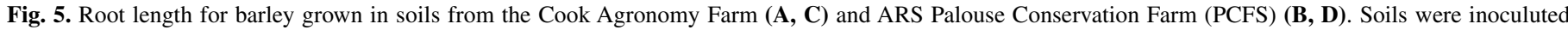

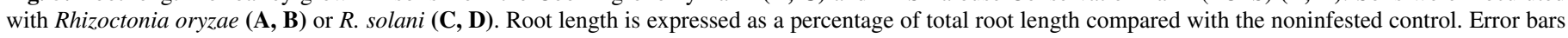
were calculated from the standard error of the mean. 
tween soils would likely not be due to differences in texture, but could be the result of variations in microbial activity in each soil.

Few differences in plant damage or disease severity were observed between soils removed from conventionally tilled and direct-seeded fields that were infested with $R$. solani AG-8 or
$R$. oryzae. Similar disease behavior was detected in both soils, suggesting that the soils may possess the same conduciveness to the pathogens. However, previous literature suggests that changes in microbial population and structure occur with direct seeding. Doran (6) found substantially greater numbers of microorganisms present in the upper $7.5 \mathrm{~cm}$ of soil direct seeded for 3 to 10 years

TABLE 1. Correlation analysis of variables from barley plants grown in Rhizoctonia solani-infested soil ${ }^{\mathrm{a}}$

\begin{tabular}{|c|c|c|c|c|c|}
\hline & Tips (no./plant) & Root length $(\mathrm{cm})$ & Disease rating $(0-8)$ & $\%$ Infected seminal roots & Seminal roots (no./plant) \\
\hline Plant height & $0.61^{*}$ & $0.43^{*}$ & $-0.66^{*}$ & $-0.60^{*}$ & $0.26^{*}$ \\
\hline Seminal roots (no./plant) & 0.16 & 0.18 & $-0.19^{*}$ & -0.14 & $\ldots$ \\
\hline$\%$ Infected seminal roots & $-0.77^{*}$ & $-0.77^{*}$ & $0.91^{*}$ & $\ldots$ & $\cdots$ \\
\hline Disease rating $(0-8)$ & $-0.84^{*}$ & $-0.78^{*}$ & $\ldots$ & $\ldots$ & $\ldots$ \\
\hline Root length $(\mathrm{cm})$ & $0.91^{*}$ & $\ldots$ & $\ldots$ & $\ldots$ & $\ldots$ \\
\hline
\end{tabular}

a All correlations marked with an asterisk $(*)$ are significant at $P<0.0001$. Additional correlations were significant with $P$ values of 0.0003 to 0.0043 .

TABLE 2. Correlation analysis of variables from barley plants grown in Rhizoctonia oryzae-infested soil ${ }^{a}$

\begin{tabular}{|c|c|c|c|c|c|}
\hline & Tips (no./plant) & Root length $(\mathrm{cm})$ & Disease rating $(0-8)$ & $\%$ Infected seminal roots & Seminal roots (no./plant) \\
\hline Plant height & $0.63^{*}$ & $0.38^{*}$ & $-0.70^{*}$ & $-0.47^{*}$ & $0.79^{*}$ \\
\hline Seminal roots (no./plant) & $0.59^{*}$ & $0.57^{*}$ & $-0.65^{*}$ & $-0.42^{*}$ & $\ldots$ \\
\hline$\%$ Infected seminal roots & $-0.67^{*}$ & $-0.55^{*}$ & $0.89^{*}$ & $\ldots$ & $\ldots$ \\
\hline Root length $(\mathrm{cm})$ & $0.85^{*}$ & $\ldots$ & $\ldots$ & $\ldots$ & $\ldots$ \\
\hline
\end{tabular}

a All correlations marked with an asterisk (*) are significant at $P<0.0001$.
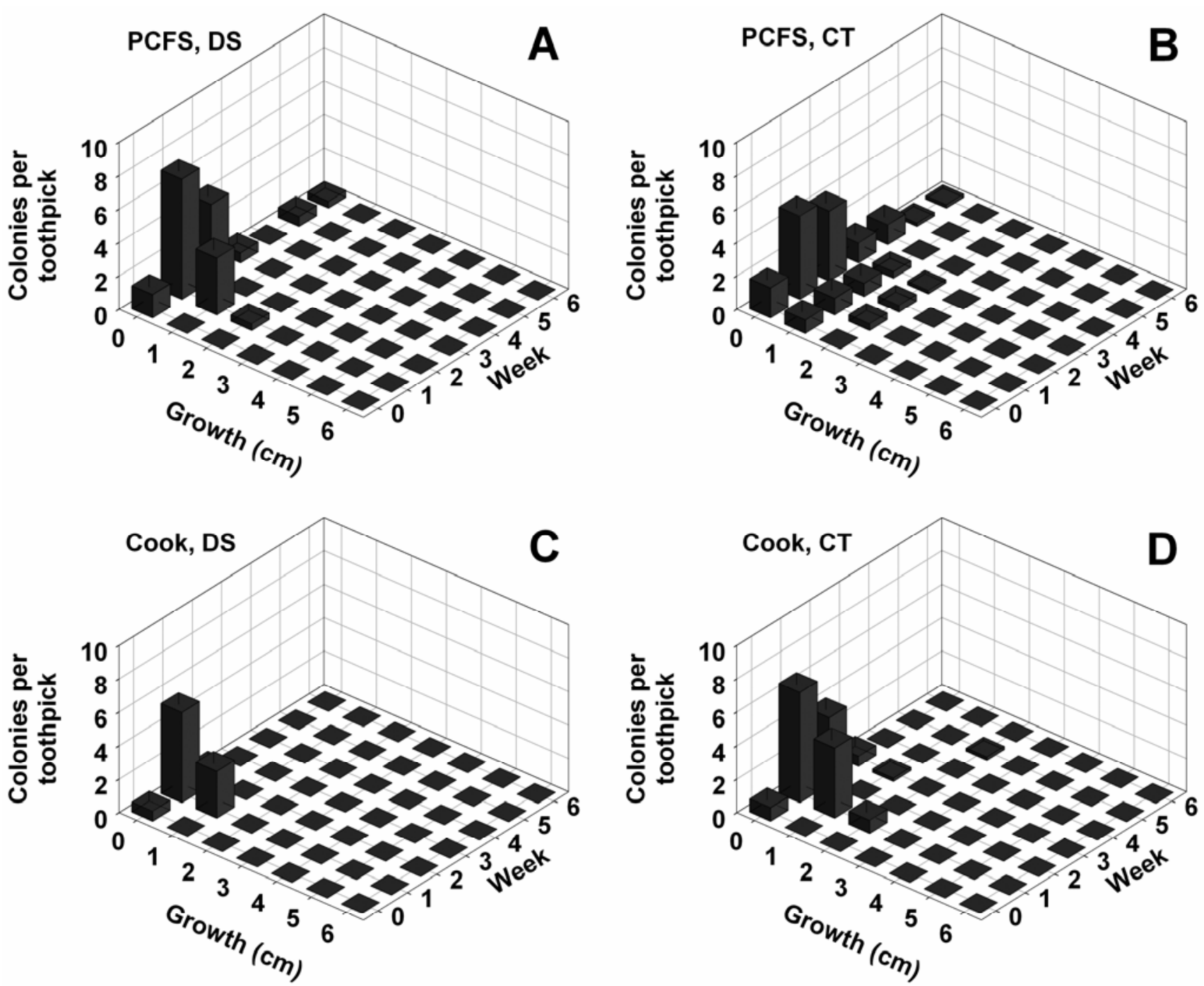

Fig. 6. Growth of Rhizoctonia oryzae from a colonized oat seed through intact soil cores from the ARS Palouse Conservation Farm (PCFS) (A, B) or the Cook Agronomy Farm $(\mathbf{C}, \mathbf{D})$. DS = direct-seeded soil and CT = conventionally tilled soil. 
versus conventionally tilled soils. At lower depths, the microbial activity was the same or reduced in direct-seeded soils versus conventionally tilled soils. This increase in microbial activity was correlated with a simultaneous increase in organic $\mathrm{C}$ and $\mathrm{N}$ as well as water content. In a separate study, similar increases in microbial biomass ( $54 \%$ greater than tilled soils) were reported in the top $7.5 \mathrm{~cm}$ of soil from direct-seeded fields that were under direct seed management for 5 to 13 years (7). In Australia, soils that were direct-seeded for either 6 or 16 years had higher organic $\mathrm{C}$ and microbial biomass and were associated with a reduced level of disease following the artificial introduction of $R$. solani inoculum compared with a tilled soil (23). A comparison of microbial biomass was made between direct seeding, stubble mulch, and conventional tillage in western Nebraska, following 16 years of a wheat-fallow rotation with each management practice (9). The microbial biomass in the top $10 \mathrm{~cm}$ increased as the amount of soil disruption decreased, resulting in the highest microbial biomass in the direct seeding and stubble mulch, and both were substantially higher than conventional tillage. Greater biomass was found in the direct-seeded plots of winter wheat compared to conventional plots throughout the growing season, with the exception of a flush of biomass immediately following tillage operations (15). Differences might also be present in the microbial biomass in the rhizosphere of plants grown with direct seeding versus conventional tillage. Increased biological activity is likely due to increased water infiltration and higher water content in the upper soil region (7).

The fact that microbial activity increases may suggest that general suppressiveness of the soil might also increase, resulting

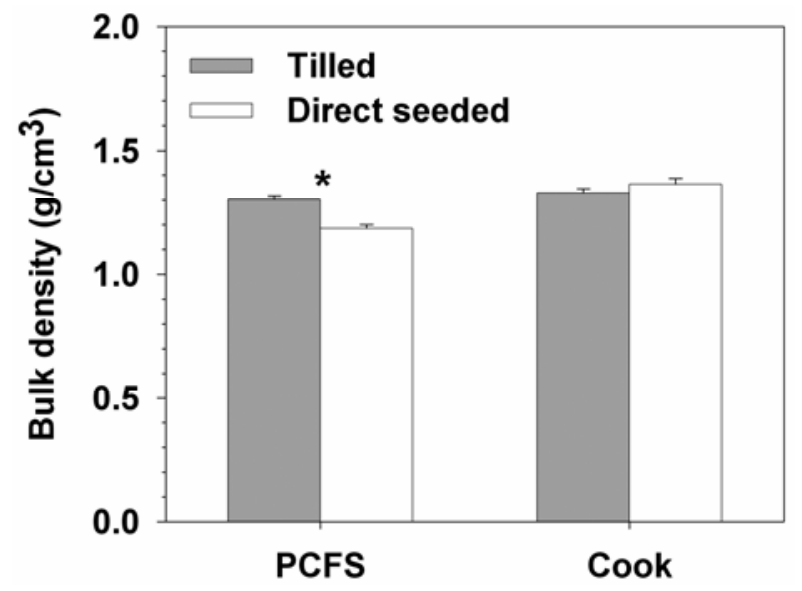

Fig. 8. Bulk density of soils from tilled and direct-seeded locations at the ARS Palouse Conservation Farm (PCFS) and the Cook Agronomy Farm. Values with an asterisk $(*)$ are significantly different using Fisher's least significant difference at $P=0.05$.
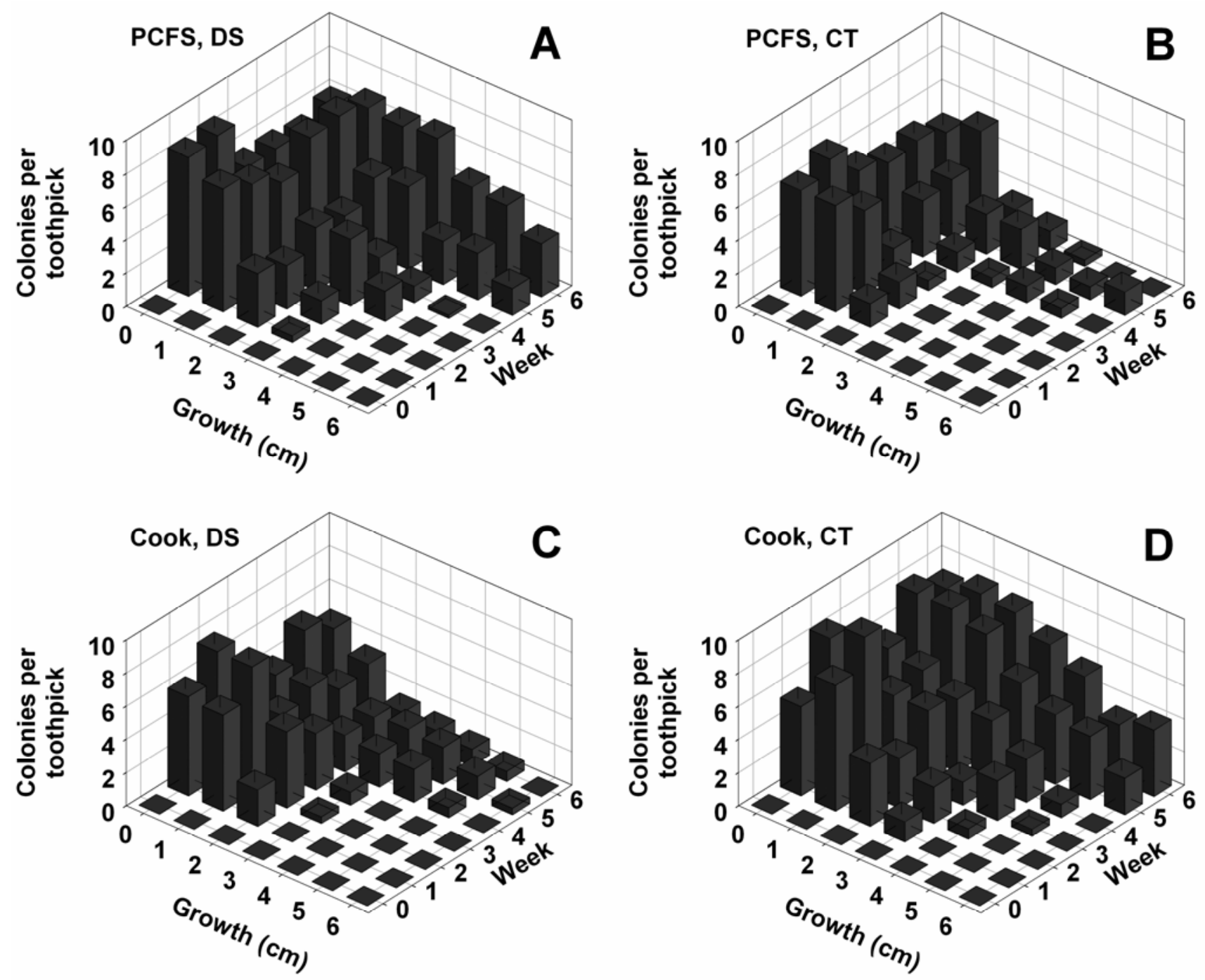

Fig. 7. Growth of Rhizoctonia solani from a colonized oat seed through intact soil cores from the ARS Palouse Conservation Farm (PCFS) (A, B) or the Cook Agronomy Farm $(\mathbf{C}, \mathbf{D})$. DS = direct-seeded soil and CT = conventionally tilled soil. 
in decreased disease incidence due to pathogens such as Rhizoctonia spp. However, Rhizoctonia spp. are very good saprophytes and survive unfavorable growing conditions by colonizing plant debris $(19,24)$. $R$. oryzae is also capable of producing microsclerotia to survive between periods of active growth. Rhizoctonia spp. might be favored by the decreased soil temperatures and increased soil moisture associated with direct-seeding. Conducting this experiment under conditions that more closely simulate the microenvironmental conditions in the field may provide different conclusions. However, attaining similar inoculum densities in direct-seeded and conventionally tilled soils to perform this type of experiment under field conditions is problematic. Using soils removed from fields in the spring also may have shown different results than those presented in this study, in which soils were collected in the fall after harvest.

Soil structure seems to be of minor importance for $R$. oryzae growth. However, greater growth of $R$. solani was observed in direct-seeded soils from ARS Palouse Conservation Farm that were direct seeded for 20 years and in conventionally tilled soils removed from the Cook Agronomy Farm when compared to soils direct seeded for 3 years. Soils with a long history of direct seeding possess improved porosity and soil structure due to increased aggregate size resulting in larger average pore diameters $(8,17)$. This might explain the increased rate of colonization in the ARS Palouse Conservation Farm soils. Otten et al. (21) previously reported slower rates of fungal growth in soils with higher bulk densities and smaller aggregate size. In a separate study, $R$. solani AG-4 was found to preferentially grow through larger pores, which would more likely be associated with soils having a lower bulk density (22). Although aggregate size was not measured in the current study, bulk density measurements closely followed aggressiveness of colonization in the various soils. Surprisingly, more growth was observed in the conventionally tilled soils from the Cook Agronomy Farm, exceeding the level of growth observed in the neighboring soil that was direct seeded for 3 years. However, this followed the trend in bulk density, with a lower bulk density in the tilled soil. In the early stages of converting a soil from conventional tillage to direct seeding, soil structure is less developed and soil compaction is likely to increase as was indicated by the increased bulk density. Results from this experiment indicate that the growth of $R$. solani AG-8 was greatest in soils direct-seeded for 20 years and lowest in the Cook Agronomy Farm soils direct-seeded for only 3 years. The soils used in the experiment reported here were Thatuna fine silty loams. A lighter or heavier soil might give very different results than those presented. Singh (34) found that $R$. solani AG-8 grew more aggressively through sand versus heavier soils. In eastern Washington, bare patch is usually only seen in intermediate to dry rainfall areas with sandy loam soils, and is rarely seen in the higher rainfall areas in the Palouse region, which has a heavier soil (fine sandy loam).

This study uncovered some basic differences in damage caused by $R$. solani AG-8 and $R$. oryzae. Previous work suggested that $R$. oryzae is only weakly pathogenic and that some isolates are nonpathogenic $(20,36)$. Recently, $R$. oryzae was found to be common in cereal fields in eastern Washington and frequently isolated from soils in higher rainfall areas (26). Paulitz et al. (27) examined isolates of $R$. oryzae from barley, tall fescue, and pea, and determined that at $16^{\circ} \mathrm{C}$, all isolates were pathogenic on winter wheat, spring wheat, and spring barley, causing significant plant stunting and root damage. In this study, $R$. oryzae caused substantial damage to barley when plants were grown in soils infested with ground $R$. oryzae-oat inoculum. The amount of disease was similar to that caused by $R$. solani AG- 8 at low and high inoculum densities; however, root loss resulting from $R$. oryzae infection was lower than that caused by $R$. solani at moderate inoculum densities ( 0.8 to $25 \mathrm{ppg})$. In addition, $R$. oryzae significantly reduced the number of seminal roots at high inocu- lum densities. At similar inoculum densities, $R$. solani AG-8 did not alter the number of seminal roots. Similar results were previously reported by Mazzola et al. (18) on wheat. They found that all $R$. oryzae isolates examined caused disease on wheat when grown at 12 or $20^{\circ} \mathrm{C}$ and using a whole oat inoculum of the pathogen, 12 out of 19 isolates were shown to cause substantial damage at both temperatures. Stunting and damping-off of barley were observed when soils at 18 and $26^{\circ} \mathrm{C}$ were inoculated with $R$. oryzae grown on a perlite-maizemeal medium, but not in soils at $12^{\circ} \mathrm{C}$ (3). In contrast, a separate study demonstrated that $R$. oryzae was nonpathogenic or only weakly pathogenic to wheat and barley at $10^{\circ} \mathrm{C}$ and moderately pathogenic at $20^{\circ} \mathrm{C}$ (20). Likewise, Smiley and Uddin (36) found that $R$. oryzae only caused slight to moderate damage in greenhouse and field trials. This present study and previous studies by Mazzola et al. (18) indicate that at above $12^{\circ} \mathrm{C}$ with a virulent isolate and sufficient inoculum density, $R$. oryzae can cause substantial plant damage on both wheat and barley. Mazzola et al. (18) suggested that there is a high degree of pathogenic variability within populations of $R$. oryzae and speculated that the isolates used in these previous studies may have been less fit. The isolate used in this study (801387) was one of eight isolates used by Paulitz et al. (27), and was shown to be the most virulent isolate on wheat and similar in virulence to other isolates on barley. The isolates used by Paulitz et al. (27) all caused significant plant stunting and reduction in total root length on both wheat and barley at $16^{\circ} \mathrm{C}$. Sequencing of the internal transcribed spacer (ITS) rDNA shows that these isolates are closely related to Waitea circinata var. circinata (P. A. Okubara, unpublished data).

In addition to differences in the severity of disease caused by $R$. solani AG- 8 and $R$. oryzae, differences in growth through intact soil cores was evident. In most cores, $R$. solani AG-8 grew very aggressively, reaching $6 \mathrm{~cm}$ within 5 weeks. $R$. oryzae also quickly spread from the inoculum; however, growth generally did not extend beyond $2 \mathrm{~cm}$. The number of colonies of $R$. oryzae recovered from each toothpick began to decline after the second week and was rarely recovered from any part of the cores by the fourth or fifth week of the study. The survival strategy for each of these two species varies somewhat. $R$ solani AG- 8 rarely forms sclerotia (38) and relies instead on the use of dead and decaying plant debris to persist in the soil. $R$. solani has a tremendous saprophytic ability and was demonstrated to grow rather large distances through soil, even in the absence of a reasonable source of organic material (10). However, $R$. oryzae readily forms numerous microsclerotia on agar media and in nature, making it less reliant on saprophytic survival over a prolonged period of time. In this study, the reduction in hyphal activity of $R$. oryzae may be due to unfavorable conditions in the soil cores stimulating $R$. oryzae to convert to a dormant sclerotial state, which would not be detected by the toothpick baiting method. Perhaps at a different soil temperature or moisture content, growth rates similar to or in excess of that seen with $R$. solani AG- 8 may have occurred.

$R$. oryzae was found to cause damping-off at the highest inoculum densities ( 80 to $250 \mathrm{ppg}$ ) as well as a reduction in the number of seminal roots. At the highest inoculum densities, the emergence of barley plants from $R$. oryzae-infested soils was delayed and overall emergence was reduced by 5 to $18 \%$ compared with the control and the same inoculum densities of $R$. solani AG-8 (K. L. Schroeder and T. C. Paulitz, unpublished data). Similar observations were previously reported on barley (27) and wheat $(18,27)$. However, this report shows that the number of seminal roots of $R$. oryzae-infected barley plants was reduced at the higher inoculum densities, unlike the previous results on wheat.

Plants infected by either $R$. solani AG-8 or $R$. oryzae compensated for increased seminal root damage by production of crown roots. This was not previously reported for cereals infected with 
Rhizoctonia root rot pathogens. This phenomenon would explain why yields are often not significantly suppressed by moderate Rhizoctonia root rot pressure in the field. Increased root growth was previously reported for wheat plants infected with take-all (1). Take-all induced an increase in the number of roots early in the infection process; however, as the plants aged and the disease progressed, the number of roots on healthy plants surpassed the number of roots present on diseased plants. Similar root growth compensation was observed in potato plants infected with isolates of $R$. solani AG-8 isolated from infected barley plants (12). Following the destruction of main roots, increased lateral root growth in the potato plants was observed. In addition to an increase in crown root numbers, a very low disease incidence was present on the crown roots, indicating that these secondary roots might be less susceptible to infection.

Changes in the microclimate due to increased crop residues on the surface of the soil may have a greater impact on disease incidence than soil compaction. Increased residues are implicated in maintaining a cooler, wetter soil in the spring, which may in turn greatly affect the microbial community, increasing the activity of both plant pathogens and natural antagonistic organisms. In this study, the soils from both direct-seeded and tilled fields were mixed, so residues were not present on the surface of the conetainers. In addition, soils were maintained at a similar moisture content and soil temperature. Thus, the microbial activities that might be present in a natural setting may not be observed in these greenhouse experiments. This is likely the primary reason for the lack of difference in disease between soils removed from direct-seeded and tilled sites at the Cook Agronomy Farm and ARS Palouse Conservation Farm.

Increased root disease incidence and severity in the transition to direct seeding remains one of the primary deterrents to the adoption of this technology in the Pacific Northwest. Many factors associated with the occurrence and development of Rhizoctonia root rot remain a mystery. In this study, soils removed from conventionally tilled or direct-seeded fields, then dried and mixed, differed little in their ability to support Rhizoctonia root rot. However, the growth of $R$. solani AG-8 through intact soil cores taken from these same fields varied with tillage history, suggesting that soil structure plays an important role. In addition, $R$. oryzae and $R$. solani AG-8 exhibited different growth rates and behavior in intact soil, as well as a different symptomatology. $R$. oryzae has the potential to cause significant and serious damage to barley plants, although damage under field conditions may be moderated by the diverse genetic variation in this pathogen and subsequent variation in parasitic fitness (18). Further work is required to understand the importance of indigenous microflora on Rhizoctonia spp. in direct-seeded soils.

\section{LITERATURE CITED}

1. Bailey, D. J., and Gilligan, C. A. 2004. Modeling and analysis of diseaseinduced host growth in the epidemiology of take-all. Phytopathology 94:535-540.

2. Baker, C. J., Saxton, K. E., and Ritchie, W. R. 1996. No-Tillage Seeding: Science and Practice. CAB International, Wallingford, UK.

3. Burton, R. J., Coley-Smith, J. R., and Wareing, P. W. 1988. Rhizoctonia oryzae and $R$. solani associated with barley stunt disease in the United Kingdom. Trans. Br. Mycol. Soc. 91:409-417.

4. Cook, R. J. 2001. Management of wheat and barley root diseases in modern farming systems. Australas. Plant Path. 30:119-126.

5. Cook, R. J., Weller, D. M., Youssef El-Banna, A., Vakoch, D., and Zhang, H. 2002. Yield responses of direct-seeded wheat to rhizobacteria and fungicide seed treatments. Plant Dis. 86:780-784.

6. Doran, J. W. 1980. Soil microbial and biochemical changes associated with reduced tillage. Soil Sci. Soc. Am. J. 44:765-771.

7. Doran, J. W. 1987. Microbial biomass and mineralizable nitrogen distributions in no-tillage and plowed soils. Biol. Fertil. Soils 5:68-75.

8. Drees, L. R., Karathanasis, A. D., Wilding, L. P., and Blevins, R. L. 1994. Micromorphological characteristics of long-term no-till and conven- tionally tilled soils. Soil Sci. Soc. Am. J. 58:508-517.

9. Follett, R. F., and D. S. Schimel. 1989. Effect of tillage practices on microbial biomass dynamics. Soil Sci. Soc. Am. J. 53:1091-1096.

10. Garrett, S. D. 1960. Biology or Root-Infecting Fungi. Cambridge University Press, Cambridge.

11. Gill, J. S., Sivasithamparam, K., and Smettem, K. R. J. 2000. Soil types with different texture affects development of Rhizoctonia root rot of wheat seedlings. Plant Soil 221:113-120.

12. Hide, G. A., and Firmager, J. P. 1990. Effects of an isolate of Rhizoctonia solani Kühn AG8 from diseased barley on the growth and infection of potatoes (Solanum tuberosum L.). Potato Res. 33:229-234.

13. Kim, D.-S., Cook, R. J., and Weller, D. M. 1997. Bacillus sp. L324-92 for biological control of three root diseases of wheat grown with reduced tillage. Phytopathology 87:551-558.

14. Kumar S., Sivasithamparam, K., Gill, J. S., and Sweetingham, M. W. 1999. Temperature and water potential effects on growth and pathogenicity of Rhizoctonia solani AG-11 to lupin. Can. J. Microbiol. 45:389395.

15. Lynch, J. M., and Panting, L. M. 1980. Cultivation and the soil biomass. Soil Biol. Biochem. 12:29-33.

16. MacNish, G. C. 1985. Methods of reducing rhizoctonia patch of cereals in Western Australia. Plant Pathol. 34:175-181.

17. Mahboubi, A. A., Lal, R., and Faussey, N. R. 1993. Twenty-eight years of tillage effects on two soils in Ohio. Soil Sci. Soc. Am. J. 57:506-512.

18. Mazzola, M., Wong, O. T., and Cook, R. J. 1996. Virulence of Rhizoctonia oryzae and $R$. solani AG- 8 on wheat and detection of $R$. oryzae in plant tissue by PCR. Phytopathology 86:354-360.

19. Neate, S. M. 1987. Plant debris in soil as a source of inoculum of Rhizoctonia in wheat. Trans. Br. Mycol. Soc. 88:157-162.

20. Ogoshi, A., Cook, R. J., and Bassett, E. N. 1990. Rhizoctonia species and anastomosis groups causing root rot of wheat and barley in the Pacific Northwest. Phytopathology 80:784-788.

21. Otten, W., Hall, D., Harris, K., Ritz, K., Young, I. M., and Gilligan, C. A. 2001. Soil physics, fungal epidemiology and the spread of Rhizoctonia solani. New Phytol. 151:459-468.

22. Otten, W., Harris, K., Young, I. M., Ritz, K., and Gilligan, C. A. 2004. Preferential spread of the pathogenic fungus Rhizoctonia solani through structured soil. Soil Biol. Biochem. 36:203-210.

23. Pankhurst, C. E., McDonald, H. J., Hawke, B. G., and Kirkby, C. A. 2002. Effect of tillage and stubble management on chemical and microbiological properties and the development of suppression towards cereal root disease in soils from two sites in NSW, Australia. Soil Biol. Biochem. 34:833-840.

24. Papavizas, G. C., and Davey, C. B. 1961. Saprophytic behaviour of Rhizoctonia in soil. Phytopathology 51:693-699.

25. Paulitz, T. C., and Schroeder, K. L. 2005. Optimization of a toothpick baiting method for quantification of Rhizoctonia species in soil. Plant Dis. 89:767-772.

26. Paulitz, T. C., Smiley, R. W., and Cook, R. J. 2002. Insights into the prevalence and management of soilborne cereal pathogens under direct seeding in the Pacific Northwest, U.S.A. Can. J. Plant Pathol. 24:416-428.

27. Paulitz, T. C., Smith, J. D., and Kidwell, K. K. 2003. Virulence of Rhizoctonia oryzae on wheat and barley cultivars from the Pacific Northwest. Plant Dis. 87:51-55.

28. Paulitz, T. C., Zhang, H., Cook, R. J. 2003. Spatial distribution of Rhizoctonia oryzae and rhizoctonia root rot in direct-seeded cereals. Can. J. Plant Pathol. 25:295-303.

29. Pumphrey, F. V., Wilkins, D. E., Hane, D. C., and Smiley, R. W. 1987. Influence of tillage and nitrogen fertilizer on Rhizoctonia root rot (bare patch) of winter wheat. Plant Dis. 71:125-127.

30. Roget, D. K., Neate, S. M., and Rovira, A. D. 1996. Effect of sowing point design and tillage practice on the incidence of rhizoctonia root rot, take-all and cereal cyst nematode in wheat and barley. Aust. J. Exp. Agric. 36:683-693.

31. Roget, D. K., Venn, N. R., and Rovira, A. D. 1987. Reduction of Rhizoctonia root rot of direct-drilled wheat by short-term chemical fallow. Aust. J. Exp. Agric. 27:425-430.

32. Rovira, A. D. 1986. Influence of crop rotation and tillage on Rhizoctonia bare patch of wheat. Phytopathology 76:669-673.

33. Schroeder, K. L., and Paulitz, T. C. 2006. Assessment of root diseases on wheat and barley in the transition from conventional tillage to direct seeding. Plant Dis. 90:1247-1253.

34. Singh, J. 2001. Effect of Abiotic and Biotic Soil Environments on Root Growth of Wheat and Soil Growth and Pathogenicity of Rhizoctonia solani AG-8. Ph.D. thesis, University of Western Australia, Perth.

35. Smiley, R. W., Ogg, A. G., Jr., and Cook, R. J. 1992. Influence of glyphosate on Rhizoctonia root rot, growth, and yield of barley. Plant Dis. 76:937-942. 
36. Smiley, R. W., and Uddin, W. 1993. Influence of soil temperature on Rhizoctonia root rot ( $R$. solani AG-8 and $R$. oryzae) of winter wheat. Phytopathology 83:777-785.

37. Smith, J. D., Kidwell, K. K., Evans, M. A., Cook, R. J., and Smiley, R. W. 2003. Evaluation of spring cereal grains and wild Triticum germplasm for resistance to Rhizoctonia solani AG-8. Crop Sci. 43:701-709.
38. Warcup, J. H., and Talbot, P. H. B. 1962. Ecology and identity of mycelia isolated from soil. Trans. Br. Mycol. Soc. 45:495-518.

39. Weller, D. M., Cook, R. J., MacNish, G., Bassett, E. N., Powelson, R. L., and Petersen, R. R. 1986. Rhizoctonia root rot of small grains favored by reduced tillage in the Pacific Northwest. Plant Dis. 70:70-73. 